\title{
Max Diamant y el SAP frente al POUM ${ }^{1}$
}

Max Diamant and the SAP in front of the POUM

\section{Reiner Tosstorff}

Departament d'Història

Johannes Gutenberg-Universität Mainz

D-55099 Mainz. Alemanya

$\bowtie$ reiner.tosstorff@uni-mainz.de

Traducción: Alejandro Acosta

Rebut: $14 / 01 / 2018$

Acceptat: 05/02/2018

\section{Resumen}

El artículo describe la actitud de Max Diamant, el representante en Barcelona del SAP, un partido socialista de izquierda alemán, aliado al POUM en el Buró de Londres, hacia este partido durante su estancia desde octubre de 1936 y abril de 1937. Criticó su política, que el SAP encontró demasiado hostil al frentepopulismo y demasiado beligerante hacia el estalinismo.

Palabras clave: Trotskismo; estalinismo; frentepopulismo; Max Diamant; Willy Brandt.

\section{Abstract}

The article describes the attitude of Max Diamant, the representative of the SAP, a German left socialist party, allied to the POUM in the London Bureau, in Barcelona between October 1936 and April 1937. He criticized their policy which the SAP found too critical towards popularfrontism and too belligerent towards Stalinism.

Keywords: Trotskyism; Stalinism; popularfrontism; Max Diamant; Willy Brandt.

\section{Sumario}

1. Algunas notas previas; 2 . El SAP en el verano de 1936: intentos de un frente popular...; 3. ...y el uso del terror de masas en la Unión Soviética (el primer Proceso de Moscú, del 19 al 24 de agosto de 1936); 4. El SAP, el Buró de Londres y el POUM; 5. El Congreso de Bruselas; 6. Max Diamant en Barcelona I (octubre-diciembre de 1936); 7. La conferencia de Katowice; 8. Max Diamant en Barcelona II (20 de febrero a 11 de abril de 1937); 9. Observaciones finales 


\section{Algunas notas previas}

A la hora de reseguir la actividad de Max Diamant, representante del SAP (Sozialistische Arbeiterpartei, Partido Socialista de los Trabajadores), en Barcelona durante sus dos estancias entre octubre de 1936 y abril de 1937, la situación de las fuentes es compleja. Diamant no dejó un conjunto propio de documentos de su estancia en la ciudad, lo que por otra parte habría sido difícilmente imaginable debido a las condiciones del exilio y la huida posteriores, empero tampoco un relato detallado y coherente en forma de Memorias. No obstante, siempre respondió voluntariosamente a las preguntas de los historiadores, como por ejemplo a las del autor de estas líneas, pero especialmente a Patrick von zur Mühlen en su obra sobre los combatientes alemanes en España'. Con todo, en una larga entrevista sobre su vida se refirió por desgracia sólo de una manera muy breve a sus vivencias en España ${ }^{2}$. En las publicaciones coetáneas del SAP no se mencionaban, por razones evidentes, los nombres de los autores, algo que también vale para la prensa del POUM (acrónimo de Partido Obrero de Unificación Marxista), el partido hermano del SAP en España ${ }^{3}$. En algunas pocas ocasiones sin embargo Diamant sí apareció bajo su pseudónimo Hans Diesel, así que normalmente sólo se puede suponer su autoría en algunos textos de la época. Con todo, desde hace algún tiempo permanece accesible el Archivo del SAP, que contiene principalmente las actas de la dirección en el exilio en París y extensa correspondencia con los elementos del SAP dispersados por Europa, entre ellos con miembros que estaban en España en la época de la Guerra Civil ${ }^{4}$. Sin embargo esa documentación debe presentar lagunas, como todas las correspondencias de ese estilo, y además le es inherente un carácter oficialista de partido, así que muchas cosas permanecen en la oscuridad. Tampoco hay, ni con una sola excepción, archivos privados de militantes del SAP que ejercieran funciones del Partido en Barcelona, ni siquiera de las varias docenas de afiliados del

1. ZUR MÜHLEN, Patrik von, Spanien war ihre Hoffnung: die deutsche Linke im Spanischen Bürgerkrieg 1936 bis 1939, Bonn, Verlag Neue Gesellschaft, 1983.

2. SCHARRER, Manfred, "Max Diamant - Erzählte Lebensgeschichte», Die Neue Gesellschaft/Frankfurter Hefte, 9 (septiembre 1988), pp. 805-814.

3. Sobre su historia véase mi detallada descripción en Die POUM in spanischen Bürgerkrieg, Frankfurt am Main, 1987, o mi compendio posterior El POUM en la revolució espanyola, Barcelona, Base, 2009. También se pueden encontrar copiosas referencias en la bibliografía en lengua española y catalana.

4. El Archivo del SAP fue escondido al estallar la guerra en Noruega y se lo redescubrió en los años 80. Ahora se encuentra en la Arbeiderbevegelsens Arkiv og Bibliotek en Oslo. La Fundación Friedrich Ebert en Bonn — a la que se ha recurrido para realizar este artículo-y el Bundesarchiv en Berlín-Lichterfelde (en el fondo del antiguo Instituto para el Marxismo-Leninismo del Partido Socialista Unificado de Alemania, el SED) disponen respectivamente de un microfilm que contiene igualmente los documentos del Archivo del SAP. Ver también LORENZ, Einhart "Das SAP-Archiv im Archiv der norwegischen Arbeiterbewegung", IWK, 1988, 2, pp. 234-244. 
SAP enviados al resto de España, que nos permitan tratar la cuestión. Entre esos miembros y dirigentes del SAP que estuvieron en Barcelona, habría que mencionar a Peter Blachstein, que vino como delegado de su organización juvenil ${ }^{5}$, y sobre todo Willy Brandt, que reemplazó a Max Diamant como representante oficial del Partido en España tras el retorno de éste a París en abril de 1937. Brandt sí dejó un considerable archivo conservado en la Fundación Friedrich Ebert. El material que se conserva allí relativo a España tiene pero también ese carácter oficialista (con la excepción de unas compilaciones de cartas con descripciones de impresiones personales y sus artículos coetáneos en prensa). Debido a sus cargos políticos ulteriores, pero también gracias a sus folletos del año 1937 sobre la Guerra Civil Española, en los cuales presentó una valoración de la situación en España desde la perspectiva de la dirección del SAP ${ }^{6}$, Brandt ha "eclipsado" desde luego el amplio rol interno de Max Diamant y ha formado la imagen de las relaciones del SAP durante la Guerra Civil, especialmente de su postura ante el POUM. Y eso a pesar que sólo permaneció activo como representante del SAP en Barcelona dos meses, de abril a junio de 1937. De ese modo, Brandt coincidió y vivió los Hechos de Mayo, que supusieron el fin de la fase revolucionaria de la Guerra Civil Española (y también que tuviera que huir a fin de evitar la represión estalinista).

Desgraciadamente, mucho de lo que podría haberse dicho de esta época (las difíciles condiciones de vida en una situación de revolución y de guerra, la consecuente actitud de los hombres, etc., bajo el punto de vista de las experiencias y observaciones de Max Diamant) debe quedar fuera debido a las carencias de las fuentes. Quien no obstante busque referencias sobre ello, las encontrará indudablemente en el entorno político de los izquierdistas socialistas internacionales y de los opositores comunistas en los círculos del POUM, en los cuales Max Diamant se movió en Barcelona y en los que él en parte es mencionado directamente?

5. Según las informaciones de la Fundación Friedrich Ebert sobre los documentos allí dejados por Blachstein, sólo se encuentran los que son posteriores al año 1945, pero sin embargo hay una colección con su correspondencia desde 1936 a 1945 en el Arbetarrörelsens Arkiv de Estocolmo (http://www.fes.de/archiv/adsd_neu/inhalt/nachlass/nachlass_b/blachstein-pe.htm [24.1.2014]), es decir con cartas enviados desde Barcelona en 1936/37. Mientras tanto, una biografía suya aparece en HEID, Ludger Joseph, Peter Blachstein: Politische Biografie eines Hamburger Sozialdemokraten (1911-1977), Hamburgo, VSA, 2014. En las páginas 79 a 103 se habla de su estancia en España, aunque se hace muy escaso uso de sus cartas y se trata sobre todo de su persecución tras los Hechos de Mayo.

6. «Ein Jahr Krieg und Revolution in Spanien. Referat des Gen. Brandt auf der Sitzung der erweiterten Partei-Leitung der SAP, Anfang Juli 1937, o. O. o. J.»; reproducido en BRANDT Willy, Berliner Ausgabe, Bd. 1: Hitler ist nicht Deutschland. Jugend in Lübeck - Exil in Norwegen 1928 - 1930, Bonn, Dietz, 2002, pp. 306-342.

7. Junto a un capítulo de las Memorias de Willy Brandt, Links und frei. Mein Weg 1930 - 1950, Hamburg, Hoffman und Campe, 1982, hay que remitirse a THALMANN, Paul y THALMANN, Clara, 
EI SAP en el verano de 1936: intentos de un frente popular...

El reto político del SAP en el verano de 1936, cuando estalló la Guerra Civil Española, era la formación de frentes populares. Eso concernía por un lado a las negociaciones sobre un frente popular del exilio alemán, y por otra parte a la evaluación general de esta solución política y con ello de la política de alianzas tal y como se había emprendido después de la creación de un frente unitario en Francia contra el despliegue de las derechas radicales en 1934 y que había llevado en gran medida a un cambio en la política de la Internacional Comunista ${ }^{8}$. No en vano la reclamación de un camino común entre los partidos obreristas había sido el punto central de la política del SAP desde su fundación en 1931. Pero lo que se desarrolló bajo la bandera del Frente Popular, ¿fue la materialización de las ideas de un frente de unidad del movimiento obrero?

Tras dejar la Internacional Comunista a un lado la lucha contra la socialdemocracia como "socialfascismo" a lo largo de 1934, el SAP tuvo en un primer momento grandes expectativas en la unidad de acción que se estaba gestando. Sin embargo pronto el SAP criticó el acercamiento de los comunistas hacia los aliados partidos burgueses de izquierda (especialmente en Francia, con el Partido Radical de renombre burgués) y con ello, paralelamente, la nueva política de alianzas de la Unión Soviética, que ahora aspiraba por encima de todo a una alianza con Francia a fin de frenar la política de la Alemania de Hitler orientada a la ruptura del orden europeo establecido en Versalles en 1919. Los acontecimientos en Francia, que desembocaron finalmente a comienzos de 1936 en una alianza electoral común, encontraron también un eco en el exilio alemán y llevaron en febrero del mismo año en París, en el hotel Lutetia, a la creación de una Comisión para preparar un Frente Popular alemán. En esa preparación de un Frente Popular el SAP formó parte ${ }^{9}$. El partido criticó no obstante la moderación programática, a la que aspiraba especialmente el KPD (Kommunistische Partei Deutschlands, Partido Comunista Alemán) con el propósito de atraer a los partidos burgueses que se oponían a Hitler, y persiguió a

Revolution für die Freiheit: Stationen eines politischen Kampfes: Moskau / Madrid / Paris, Hamburgo, Association, 1977; LOW, Mary y BREÁ, Juan, Rotes Notizbuch (Spanien 9. 8. - 28. 12. 1936), Hamburgo, Nautilus, 2002; ORWELL, George, Mein Katalonien: Bericht über den Spanischen Bürgerkrieg, Zúrich, Diogenes, 1975; HORN, Gerd-Rainer (ed.), Letters from Barcelona: an American Woman in Revolution and Civil War: with some material from Charles Orr, Basingstoke, AIAA, 2009.

8. En este punto no se puede pasar por alto una visión general de las causas de fondo y las dimensiones de esta política. Sobre ello se puede encontrar información detallada y referencias bibliográficas en la obra general, de la que nos interesa aquí las consideraciones sobre el Frente Popular alemán en el exilio, LANGKAU-ALEX, Ursula, Deutsche Volksfront 1932-1939: zwischen Berlin, Paris, Prag und Moskau, Bd. 3, Berlin, Akademie Verlag, 2005.

9. Especialmente sobre ello, junto al trabajo de Ursula Langkau-Alex, BREMER, Jörg, Die Sozialistische Arbeiterpartei Deutschlands (SAP): Untergrund und Exil 1933 - 1945, Frankfurt am Main, Campus Verlag, 1978, pp. 171-184. 
continuación la creación de un «bloque proletario», una alianza especial de los partidos obreristas dentro del marco de esa alianza de Frente Popular.

En el socialismo internacional de izquierdas opuesto a la Tercera Internacional, especialmente en el Buró de Londres ${ }^{10}$, al cual pertenecían el SAP y el POUM de España, se vio en la nueva política comunista un giro a la derecha, una injustificable aproximación a las fuerzas burguesas "de izquierda» 0 , mejor dicho, el sometimiento a ellas y la renuncia a derribar al capitalismo. Frente de Unidad y Frente Popular no eran compatibles. Un Frente Popular se volvería al final contra el movimiento obrero revolucionario, como en 1917 en Rusia, o en 1918 en Alemania. Estos fueron argumentos que se escucharon en el último Congreso del Buró de Londres previo a la Guerra Civil en España (del 8 al 10 de mayo de 1936 en París), sin ser verdaderamente polemizados o discutidos a fondo. Willy Brandt narró posteriormente la polémica con el representante del POUM presente, Joaquín Maurín, de la siguiente manera: «Nosotros estamos por el Frente Popular porque estamos en contra - esas palabras se me quedaron grabadas cuando oí a Joaquín Maurín en mayo de 1936-. La fórmula no era convincente, se engendró por excesivo tacticismo. (...) Lo que -en la más benigna lectura - pudieran significar las anti-consignas era una estrategia, orientada más allá del Frente Popular»"1. En el acta no oficial de ese encuentro, que la dirección del SAP en el extranjero envió a sus afiliados a diferentes lugares, se dice concisamente: "El compañero Maurín ha manifestado claramente que él y su partido están de hecho en contra del Frente Popular» ${ }^{12}$.

El 17 de julio se inició en España el golpe de Estado de los generales contra el gobierno del Frente Popular resultante de las elecciones legislativas de febrero, un gobierno de partidos republicanos burgueses de izquierda en el que tanto los socialistas como el Partido Comunista de España no participaban directamente ${ }^{13}$. La reacción al proceder

10. El nombre oficial era Buró Internacional de Unidad Socialista Revolucionaria, pero debido al lugar de su sede adoptó el nombre más usual de Buró de Londres. Sobre esa asociación y las discusiones allí llevados a cabo sobre la política frentepopulista BUSCHAK, Willy, Das Londoner Büro: Europäische Linkssozialisten in der Zwischenkriegszeit, Ámsterdam, 1985, pp. 189-201, y sobre la reunión del Buró p. 202. Especialmente sobre el SAP véase también BREMER, Jörg, Die Sozialistische Arbeiterpartei Deutschlands,... op. cit., pp. 166-184.

11. BRANDT, Willy, Links und frei,... op. cit., p. 240.

12. Circular 5/36 de 28. 5. 1936. (Correspondencia General, Archivo Willy Brandt en la Fundación Friedrich Ebert [en adelante AWB]). Allí se reproduce el informe detallado de Maurín sobre la situación en España y la situación del POUM. Al final se pone: «Por sugerencia de Willy Brandt, se decidió enviar un saludo a los trabajadores de España y especialmente al POUM».

13. Por razones de espacio, se omite aquí enumerar una bibliografía general de obras fundamentales sobre la Guerra Civil Española. En todo caso son fáciles de localizar e identificar. Solamente por la particular importancia de Cataluña para este artículo se refiere aquí la siguiente obra historiográfica sobre los acontecimientos revolucionarios allí, que integra el papel del POUM en su contexto: PAGĖS BLANCH, Pelai, Cataluña en guerra y en revolución: 1936-1939, Sevilla, Espuela de Plata, 2007. 
de los militares fue más que sólo una guerra civil arquetípica entre dos bandos políticos enfrentados. El golpe de Estado, que debía prevenir una supuesta revolución comunista, desató una revolución ciertamente surgida como un movimiento espontáneo que desbordó ampliamente al aparato del Estado y forzó al gobierno a repartir armas entre las organizaciones obreras y sindicales. En muchas partes del país en las que el golpe no triunfó inmediatamente el colapso del Estado condujo a una profunda agitación social, a una intervención de las relaciones capitalistas-burguesas en forma de adquisiciones de empresas por las plantillas de trabajadores y expropiaciones a los propietarios agrícolas por parte de los trabajadores agrícolas y pequeños arrendatarios. La máxima expresión de este movimiento revolucionario se encontró en Cataluña a razón del importante papel y la larga tradición de los movimientos anarquistas y sindicalistas en la región, en la que eran hegemónicos y en la que el marxismo apenas había logrado presencia. Junto al sindicato CNT (Confederación Nacional del Trabajo) y la federación de los grupos anarquistas "específicos», la FAI (Federación Anarquista Ibérica), tenía no obstante cierto papel el socio aliado del SAP, el POUM (cuyas raíces se encontraban también en la CNT).

Consecuencia del desarrollo revolucionario en España fue que los golpistas, sólo unos pocos días después del comienzo del levantamiento, obtuvieran el apoyo del "campo fascista", esto es, Alemania e Italia, mientras que las potencias occidentales, encabezadas por Gran Bretaña y seguidamente por Francia, rechazaron apoyar a la República Española. Una España fascista para esas potencias no representaba un desafío importante, mientras que una revolución en España habría sido vista como una amenaza, especialmente para los grandes inversores británicos en España. En lugar de apoyar la República, las potencias occidentales llevaron a cabo una política de No Intervención: ninguna potencia extranjera debía apoyar a ninguno de los dos bandos. Con esto no sólo el gobierno legal de Madrid (con derecho, por ejemplo, a comprar armas en el extranjero) fue puesto al mismo nivel que los generales golpistas. A parte de eso, por encima de todo, se vio en la práctica que pese a hacer eso la intervención fascista-nacionalsocialista no se interrumpió ni un solo día, a despecho que Alemania e Italia habían puesto su firma en el Acuerdo de No Intervención. Todo eso tuvo como resultado que pronto la República encontrara apoyo solamente en la Unión Soviética, que inicialmente (y claramente en las primeras semanas decisivas) tampoco hubiera dado ningún apoyo si no hubiera sido por razones estratégicas de suministro de armas a la República y, como se vería, ese apoyo no sólo sería pagado con el oro español, sino que la URSS también exigiría un precio político.

...y el uso del terror de masas en la Unión Soviética (el primer Proceso de Moscú, del 19 al 24 de agosto de 1936)

Para contextualizar la evolución de los acontecimientos hay además otro hecho importante, que no debe pasarse por alto: el comienzo del «Gran Terror» en la Unión So- 
viética, a menudo llamado eufemísticamente "depuraciones", que se inició con el primer Proceso de Moscú del 19 al 24 de agosto de 1936 contra una serie de antiguos dirigentes del partido bolchevique que se habían opuesto temporalmente a Stalin en la década de 1920. Esta dinámica se intensificó en los meses siguientes hasta ser una persecución masiva que afectó no sólo al Partido sino a la sociedad soviética en general, algo que no podremos analizar más a fondo en estas páginas ${ }^{14}$.

En el análisis del SAP y especialmente de Max Diamant se estableció una conexión clara de ese hecho con el desarrollo de los acontecimientos en España. Diamant estaba entonces ocupado como miembro de la dirección del SAP en París dedicado sobre todo a cuestiones internacionales ${ }^{15}$, y en septiembre plasmó en el periódico del SAP, el Neue Front, la relación que veía entre España y el Gran Terror en la Unión Soviética. A diferencia de lo que aseveraba la propaganda de los golpistas, el país no se encontraba en una revolución siguiendo las órdenes de la Unión Soviética. Tampoco había acudido Stalin en auxilio de la República en las primeras semanas decisivas de avance de las tropas de Franco, que debían agradecer el apoyo de los alemanes y los italianos, ya que la URSS se había adherido a la política de No Intervención iniciada por Gran Bretaña y Francia. Este desarrollo de los hechos contribuyó al agravamiento de las tensiones dentro del Partido Comunista de la Unión Soviética en un contexto de creciente desigualdad social y de debilitamiento del desarrollo económico, constataba Diamant. A partir de entonces Stalin habría reaccionado a esas críticas empleando la persecución y el Terror en el seno del Partido ${ }^{16}$.

Sin embargo, esta referencia correcta en sí misma al "contexto español» se publicó precisamente en el momento en que, por consideraciones de política exterior, Stalin dio un giro a favor de la intervención en España. Empezaron los suministros de armas, gracias a los cuales especialmente en las siguientes semanas el ataque de Franco a la capital pudo ser refrenado. Sin embargo no se pensó en un apoyo a la revolución social en

14. Sobre la valoración del terror estalinista en el SAP véase BREMER, Jörg, Die Sozialistische Arbeiterpartei Deutschlands,... op. cit., pp 198-203; sobre la reacción del socialismo internacional de izquierdas BUSCHAK, Willy, Das Londoner Büro,... op. cit., pp. 266-276; sobre sus efectos en el exilio LANGKAU-ALEX, Ursula, Deutsche Volksfront 1932-1939, Bd. 2,... op. cit., pp. 177-205.

15. Entre su redacción apareció también una recopilación de material, Revolution in Spanien, en dos números, en septiembre de 1936 y luego en junio de 1937, es decir, antes y después de su estancia en Barcelona. Vid. MAAS, Lieselotte, Handbuch der deutschen Exilpresse 1933 - 1945. Bd. 4, Die Zeitungen des deutschen Exils in Europa von 1933 bis 1939 in Einzeldarstellungen, Múnich, 1990, Carl Hanser, p. 374; SCHLÜNDER, Dagmar y FABIAN, Walter, Die Presse der Sozialistischen Arbeiterpartei Deutschlands im Exil 1933 - 1939: eine analytische Bibliographie, München, Hanser, 1981, p. 10.

16. "Zur Entwicklung der Sowjetunion. Prozeß und Stalin-Politik», Neue Front, 17 (septiembre de 1936). Sobre la autoría del artículo, que fue publicado anónimamente, véase LANGKAU-ALEX, Ursula, Deutsche Volksfront,... op. cit., p. 196. 
España, como se verá más adelante. Muy contrariamente, Stalin temía una prosecución de los acontecimientos tal, que llevara al fortalecimiento de otras fuerzas españolas en detrimento del Partido Comunista de España. El control político sobre el tráfico de armas debía garantizarse. A fin de asegurar eso y de neutralizar a las fuerzas políticas de izquierda "indeseables", bien pronto el terror estalinista también se extendería por España.

\section{El SAP, el Buró de Londres y el POUM}

Ahora bien, ¿qué era exactamente el POUM? Günter Grass lo definió en 1965 en una obra teatral con la que respondió a la campaña de odio de la derecha contra Brandt, el combatiente de la España roja, de la siguiente manera: "El POUM (Partido Obrero de unificación Marxista), era un partido obrero español de izquierda socialista que, dentro del bando republicano, luchó en favor de los comunistas y fue perseguido como partido trotskista con los métodos estalinistas»17. Apenas hay nada más que añadir.

El POUM se había formado en 1935 a partir de la unión de dos partidos que desde comienzos de la década de 1930 habían quedado al margen de la órbita del Partido Comunista de España por su oposición al estalinismo: por un lado, el Bloc Obrer i Camperol $(B O C)$, y por el otro el trotskista Izquierda Comunista de España. En este sentido el POUM se entendía como un partido comunista opositor, aunque se concebía a sí mismo como el representante de una transición fluida hacia el socialismo internacional de izquierdas (también el SAP se entendía a veces como una fuerza de oposición verdaderamente comunista, como había sido el KPD en sus orígenes). Con todo, debido a sus orígenes, el POUM siempre tuvo que luchar por quitarse la etiqueta de "trotskista», a pesar que a mediados de los años 30 habían surgido diferencias con Trotsky y con el núcleo internacional del trotskismo, mientras que sus miembros, aunque ciertamente con diferentes matices de cada uno, respetaban a Trotsky como personalidad revolucionaria y le defendían frente a las ofensivas de la propaganda estalinista. Los cabecillas del POUM fueron en primer lugar su secretario general Joaquín Maurín, que ya había dirigido el BOC, aunque al producirse el estallido de la Guerra Civil se encontraba en la zona controlada por los franquistas y finalmente fue arrestado. Con eso quedó fuera y fue sustituido por Andreu Nin, anteriormente portavoz de los trostskistas españoles de Izquierda Comunista; Nin había vivido en la Unión Soviética entre 1921 y 1930 siendo secretario adjunto de la Internacional Sindical Roja, y había apoyado la lucha de Trotsky contra Stalin. El POUM había surgido en un contexto de creciente radicalización en España, después de que la Repú-

17. Esta pieza teatral, escrita y publicada durante la campaña electoral parlamentaria en 1965 , pero que realmente se basó en acontecimientos de la campaña electoral de cuatro años antes, se reeditó en GRASS, Günter, Werkausgabe in zehn Bänden, Bd. 8: Theaterspiele, Darmstadt, Neuwied, 1987, pp. 381-396; la cita aparecía en el epílogo, en la página 396. 
blica proclamada en 1931 hubiera podido llevar a cabo su obra reformista sólo al principio. Su epicentro fue Cataluña, el centro de la industria y con ello del movimiento obrero en el Estado español. Era un partido pequeño aunque con influencia sobre las masas en ciertas zonas. Por un lado desafió la hegemonía anarcosindicalista sobre el movimiento obrero catalán, y por el otro lado estaba enfrentado a un nacionalismo catalán de izquierdas que contaba con una amplia base social.

Una de las dos organizaciones fundadoras del POUM, el Bloc Obrer i Camperol, ya había tenido antes de la unión en 1935 contactos con el Buró de Londres, al mismo tiempo que los trotskistas habían manifestado a pesar de las coincidencias programáticas con Trotsky una serie de diferencias tácticas. Parece ser que el SAP veía preferible que el BOC fuera de la mano con el ala izquierda del PSOE del futuro Presidente del Consejo de Ministros Largo Caballero (en la presidencia de septiembre de 1936 a mayo de 1937). En cualquier caso eso fue objeto de una discusión con representantes del BOC en París en verano de 1935 en casa de Boris Souvarine poco antes de la fusión que dio lugar al POUM. Max Diamant había participado también en esa discusión ${ }^{18}$. Con todo y no obstante, después de la creación del POUM la relación con el Buró de Londres siguió siendo decisiva y, representado por Maurín, el POUM participó como miembro en el Congreso del 8 al 10 de mayo de 1936 en París, cuatro meses después de las elecciones en España que habían dado la victoria a la coalición electoral de izquierdas y cinco días después de la primera vuelta electoral en Francia, que presagiaba una victoria similar de las izquierdas. Willy Brandt narró su impresión de ello en sus Memorias, que señalaban también las diferencias políticas del SAP con el POUM (sobre todo en la opinión sobre el Frente Popular), como ya se ha mencionado anteriormente.

Una decisión de ese Congreso, a la vista del aumento de las tensiones internacionales, fue la convocatoria de un Congreso Antibelicista propio a través del Buró de Londres para el otoño de 1936. El estallido de la Guerra Civil Española dos meses más tarde transformó el marco para ese Congreso absolutamente.

\section{El Congreso de Bruselas}

Finalmente el Congreso tuvo lugar con un gran retraso del 31 de octubre al 1 de noviembre de 1936 en Bruselas ${ }^{19}$. En él estuvo representado un amplio arco del socialismo de izquierdas y de la oposición comunista más allá de la Segunda y la Tercera Internacional. En el centro de atención estaba la relevancia de la Revolución en España y su impac-

18. Comunicación oral de Max Diamant, 26 de febrero de 1981.

19. Una descripción general en BUSCHAK, Willy, Das Londoner Büro,... op. cit., pp. 223-234. En particular sobre la actuación del POUM TOSSTORFF, Reiner, Die POUM in spanischen Bürgerkrieg,... op. cit., pp. 297-300. 
to en la situación internacional. Con el POUM ese espectro internacional de la izquierda socialista contaba con un partido que jugaba un importante papel en el epicentro de la Revolución, en Cataluña. Sólo cupo la solidaridad con el partido. Y es que a pesar de los exitosos contraataques (fueron las semanas de ataque de las fuerzas golpistas sobre Madrid) las expectativas seguían siendo grandes. La revolución española podría ser el preludio de una amplia lucha contra el fascismo, la chispa que desencadenaría la revolución europea. Las expectativas estaban en el aire, España y especialmente Barcelona y Cataluña podían representar lo que Petrogrado y Rusia habían supuesto para la formación de la Tercera Internacional al final de la Primera Guerra Mundial.

Sin embargo, también aquí se hicieron notar de nuevo las sutiles diferencias entre el SAP y el POUM, derivadas de los esfuerzos del SAP por constituir un Frente Popular alemán del exilio. Ambos se encontraban en un momento crucial. El POUM criticó que el SAP hacía una oposición demasiado vacilante contra la política del Komintern. En lo que sí estuvieron de acuerdo todos los participantes fue en la relevancia central de la Revolución española para una contraofensiva que enfrentara el ascenso del fascismo en Europa. En cualquier caso, se acordó celebrar un gran Congreso en Barcelona en la primavera del año siguiente.

\section{Max Diamant en Barcelona I (octubre - diciembre de 1936)}

Después del estallido de la Revolución española, muchos militantes de las organizaciones del Buró de Londres se apresuraron a ir a Barcelona. En las Memorias ${ }^{20}$ antes mencionadas se encuentran numerosas referencias a la amplia representación internacional presente en Barcelona y entre la cual también estuvieron algunos miembros del $\mathrm{SAP}^{21}$. Algunos fueron desde allí al combate en el frente de Aragón, tal y como George Orwell, miembro del Partido Laborista Independiente, partido británico aliado del $\mathrm{POUM}^{22}$, tan detalladamente expuso en su libro Homenaje a Cataluña. No pocos se encargaron de tareas y asuntos en Barcelona en colaboración con el POUM. Para su coordinación, pero también con vistas al Congreso previsto en Bruselas, se estableció una Subsecretaría vinculada al Buró de Londres ${ }^{23}$ : a ésta perteneció Max Diamant en representación del SAP. Casi al mismo tiempo, el Buró Internacional de Organizaciones Juveniles Revolucionarias, que había estado trabajando en estrecha colaboración con el Buró

20. Véase nota a pie de página 7.

21. En varias circulares ( $N^{\circ} 7 / 36$ de 10 de agosto, No 8/36 de 28 de agosto y No 10 de 14 de octubre, WBA) la central extranjera del SAP pidió entre sus miembros pilotos y afiliados con formación médica y militar entre otras para ir a luchar a España.

22. El ILP era la única organización británica integrada en el Buró de Londres.

23. BUSCHAK, Willy, Das Londoner Büro,... op. cit., p. 234. 
de Londres desde 1934 y que desde entonces había tenido su sede en Oslo, se trasladó a Barcelona ${ }^{24}$.

Max Diamant fue enviado por el SAP en octubre de 1936 a la capital catalana como representante oficial, en una fecha bastante tardía. Hasta entonces el SAP no disponía de ningún representante directo, lo que plantea la pregunta de si, teniendo en consideración la gran relevancia de los sucesos de España, ese interés tardío no expresaba y se debía a razones políticas, concretamente a las ya abiertas diferencias sobre la política de frentes populares. Max Diamant tampoco participó en el Congreso de Bruselas, de cuyo transcurso y resoluciones estuvo naturalmente informado perfectamente. A partir de octubre, él estuvo a la cabeza del grupo formado por una buena docena de miembros del SAP en España, la mayoría de los cuales se encontraban en Barcelona o en el frente de Aragón ${ }^{25}$.

Por otra parte además, Diamant también contribuyó en el trabajo internacional del POUM. No en vano al llegar a Barcelona se encontró un gran caos en el aparato de propaganda internacional del POUM establecido después del 19 de julio. Por una parte eso era la consecuencia para un partido pequeño de quedar desbordado por la súbita fuerza abrumadora de los acontecimientos, pero por el otro lado también era un indicio de las diferencias surgidas en la dirección del POUM. Formalmente el Secretario Internacional del POUM era Julián Gorkin, quien quería trabajar en estrecha colaboración con el Buró de Londres y representó también al POUM en las reuniones del Buró que habían tenido lugar en París ${ }^{26}$. Otro miembro de la dirección, Juan Andrade, uno de los impulsores del movimiento trotskista en España, instó también intensamente al trabajo internacional, si bien propugnaba más bien ampliar la colaboración con otros grupos no solamente a la izquierda del SAP, sino también que se opusieran abiertamente al Buró de Londres. Muchos de ellos disponían de sus propios representantes en Barcelona. El fondo político de esa apuesta residía en el rechazo decidido de Andrade a la política de frentes populares, entendida como una política de alianzas simbióticas de clase al incorporar fuerzas burguesas. Andrade criticó una orientación que entendía que se hacía a costa de la autonomía de los revolucionarios y se posicionó decididamente contra las alianzas políticas "limitadoras". Por esa razón se produjeron fricciones en la dirección del POUM, que a la

24. Willy Brandt era representante en ese tiempo del SAP en Oslo, y antes que él iba a ser representante en Barcelona Peter Blachstein en un primer momento. Véase sobre esto los interesantes datos en LORENZ, Einhart, Willy Brandt in Norwegen: die Jahre des Exils 1933 bis 1940, Kiel, Neuer Malik, 1989.

25. Visiones sensiblemente divergentes sobre los miembros del SAP en España en BREMER, Jörg, Die Sozialistische Arbeiterpartei Deutschlands,... op. cit., p. 188.

26. En las circulares de la Central Extranjera del SAP (o, mejor dicho, Dirección del Partido, denominación tal y como se modificó en la Conferencia de Katowice) en el WBA o en el SAP-Exilarchiv se hallan una serie de protocolos de esas reuniones en París, en los cuales se articulaba también la creciente crítica del SAP. 
postre repercutieron en la relación entre el POUM y el SAP. Eso se tradujo en el aspecto de la cooperación internacional en una situación pendular de acercamiento y de enfrentamiento. Y en ningún lugar hubo esa suerte de fricciones entre grupos tan diversos como con los alemanes ${ }^{27}$.

En un primer momento, Max Diamant pudo hacer valer su influencia. Entre los socios extranjeros que se habían unido ahora al POUM se formaron grupos según el idioma que hablaran. Su dirección y coordinación fue asumida, por insistencia de Diamant, por partidos miembros del Buró de Londres, aún cuando no todos estos estaban en relación con sus países de origen e incluso a menudo pertenecían a organizaciones en fuerte disputa con el Buró de Londres. Pero en un primer instante para el POUM sí fue decisiva su propia pertenencia al Buró de Londres. Además la Subsecretaría ya mencionada llevó a cabo su trabajo con una implicación enérgica.

Desde agosto de 1936 el POUM había publicado y distribuido boletines de propaganda en diferentes idiomas; la versión alemana aparecía con el título Informationen des $P O U M^{28}$. Esos boletines serían ahora reemplazados por una revista impresa cuyo título era La Revolución española (el título aparecía en cada idioma respectivo). La versión aparecida más frecuentemente era la francesa, de la que desde principios de septiembre de 1936 hasta mayo de 1937 aparecieron un total de 16 números. Luego a mediados de diciembre aparecería una revista en alemán (Die spanische Revolution). El redactor jefe durante su estancia en Barcelona fue Max Diamant; otros colaboradores fueron dos miembros del SAP, Peter Blachstein (que lo compaginaba con su trabajo para las Juventudes del SAP en el Buró Internacional de Organizaciones Juveniles Revolucionarias) y Herbert Wolf como responsable técnico, que murió en marzo de 1937 cerca de Huesca cuando se unió a una visita al frente durante una ofensiva ${ }^{29}$. Una vez Max Diamant emprendió su viaje de vuelta a París en abril 1937, fue reemplazado en su trabajo en la redacción por su relevo como representante del Partido, Willy Brandt, algo de lo que se hablará más adelante. Hasta finales de mayo de 1937 aparecieron 7 números de la revista, apareciendo uno mensualmente y finalmente dos números en mayo, uno antes de los llamados Hechos de Mayo y otro después con materiales e informaciones sobre los enfrentamientos. En primer plano aparecía normalmente información sobre la evolución en España, sobre

27. Así las opiniones de Max Diamant, Comunicación Oral de 26 de febrero de 1981. De todos modos también lo muestran los escritos de testigos presenciales mencionados arriba en la nota a pie de página 7, que en los grupos de hablantes de otros idiomas también coexistía un amplio espectro político, con las consecuentes disputas que eso comportaba. Véase también el resumen en BUSCHAK, Willy, Das Londoner Büro,... op. cit., p. 235.

28. Sobre las publicaciones internacionales del POUM vid. TOSSTORFF, Reiner, Die POUM in spanischen Bürgerkrieg,... op. cit., p. 296.

29. Véase su minucioso homenaje por parte de Max Diamant, que está documentado junto con otros discursos y artículos en el número 5 de mediados de abril de 1937. 
las transformaciones revolucionarias como las colectivizaciones en diferentes sectores económicos, como por ejemplo reportajes de empresas concretas, o sobre las columnas de milicianos, los combates en el frente o el papel de las mujeres y de los jóvenes. También tenían un peso destacable los artículos de los líderes del POUM o las resoluciones de sus órganos rectores, así como la información sobre la propia actividad del partido, aunque también se informaba sobre las muestras de solidaridad y cooperación internacional con el POUM, por ejemplo a través de las actividades del SAP o de las labores del Buró de Londres en relación a España. Muy pronto volvió a ponerse en el foco de atención la ofensiva del Partido Comunista contra el POUM y la tentativa, mediante el apoyo soviético como argumento, de debilitar la Revolución. Más allá de los artículos de los dirigentes del POUM y similares, todas las demás contribuciones no aparecían firmadas; eso hace naturalmente que más allá de lo que es el trabajo editorial general, no podamos saber qué fue escrito por el propio Max Diamant.

Otro instrumento de la propaganda internacional del POUM fueron las retransmisiones de radio en lengua alemana, que según Peter Blachstein llegaron a ser oídas incluso en el Reich ${ }^{30}$. Blachstein fue el principal responsable, aunque sin duda Max Diamant tuvo que estar involucrado de una manera u otra en las retransmisiones. Ciertamente las labores informativas del POUM debieron beneficiar a la prensa del SAP, como se ve al echar un vistazo a su prensa ${ }^{31}$.

Esta primera parte de la estancia de Diamant en Barcelona ha dejado pocos indicios en el Archivo del SAP. Las carpetas 165 a la 168 abarcan la correspondencia de España entre 1936 y 1937; esta correspondencia empezó fundamentalmente a finales de 1936, sin revelar por qué no se incluye nada de los primeros meses después del comienzo de la guerra civil. Sin embargo, se puede encontrar una impresión general de los deberes y problemas políticos en los primeros meses de la guerra en una compilación de cartas sobre la "cuestión española» de un tal "compañero Hans", esto es decir, de Max Diamant, cuyo seudónimo era Hans Diesel, que fue enviada como apéndice a una carta circular de la dirección del partido el 1 de junio de $1937^{32}$. Ese compendio documental ya mostraba entre letras las crecientes diferencias con el POUM, especialmente sobre la cuestión de los frentes populares, en el marco de los numerosos reveses que había sufrido la Revolu-

30. TOSSTORFF, Reiner, Die POUM in spanischen Bürgerkrieg... op. cit., p. 297.

31. Sobre esto se puede ver el sinfín de artículos sobre la Guerra Civil Española, fácilmente accesibles con sólo consultar el índice, especialmente en el periódico del SAP Neue Front, como queda comprobado en FABIAN, Walter, Die Presse der Sozialistischen Arbeiterpartei Deutschlands im Exil 1933 - 1939,... op. cit. Las dos colecciones especiales de materiales con el título de Revolution in Spanien compiladas por Diamant ya han sido mencionadas anteriormente (nota 15).

32. Un anexo de 16 páginas a la circular 12/1937 en: Carpeta 16, documento 22. Una carta del 18 de abril de 1937 de Diamant al ILP, el miembro británico en el Buró de Londres, después de su definitivo retorno a París, haciendo un repaso retrospectivo a su estancia en Barcelona en: Anexo a la Circular $\mathrm{N}^{\circ} 9 / 37$ de 25 de abril, WBA. 
ción española desde el cambio de año. Las tres primeras páginas contienen fragmentos, extractos, relativos al período previo a su primer viaje de vuelta a París en diciembre de 1936 y dan una idea de sus opiniones y sus actividades. Una de sus preocupaciones centrales era el enfrentamiento con las "sectas de todos los matices», los representantes de los grupos que estaban a la izquierda del Buró de Londres y que, a menudo, como habían llegado muy pronto a Barcelona, habían ocupado puestos en el aparato del POUM. La mayoría de veces los calificaba en general de trotskistas, algo que en pocas ocasiones se usaba como descalificativo. Un grupo que lo turbaba sobremanera fue el de los comunistas de la denominada Oposición de Derecha articulados alrededor de Brandler y Thalheimer, un grupo que era poco sospechoso de estar cerca del trotskismo. Sin embargo, siempre que recibió promesas que los miembros de esos grupos serían removidos de sus posiciones oficiales en el POUM, lamentó la tenacidad con la cual esos anuncios fueron implementados. Él entendió que eso no sólo se debía a las diferentes opiniones políticas en el seno de la dirección del POUM, en la que se percató de la existencia de una corriente contraria al SAP y crítica con sus posiciones. Por otra parte entre sus quejas también aparecían comentarios que revelaban su procedencia y su huella en el bien organizado movimiento obrero alemán: "Aquí el trabajo avanza muy lentamente. La palabra que en ruso se dice 'seijtschas' aquí se dice 'mañana' y juega el mismo papel preponderante en la vida", apuntó él el 10 de noviembre, sólo unas pocas semanas después de su llegada.

A finales de diciembre Diamant partió primero a París, donde habló largo y tendido con los líderes del partido, y de allí fue a la conferencia del SAP, que se celebró en Checoslovaquia, oficialmente en Katowice, aunque en realidad tuvo lugar en Ostrava, en la región de los Sudetes ${ }^{33}$.

\section{La conferencia de Katowice}

En la conferencia de Katowice, cuyos días concretos de celebración no se desprenden ni de los documentos del Archivo del SAP y naturalmente tampoco en el reportaje aparecido en el periódico del SAP, aunque tuvo que tener lugar según Willy Brandt a principios de enero, se debía hacer un balance de las actividades con los representantes del Partido tanto en el exilio como en el interior después del último Congreso del Partido de marzo de 1933 y después sólo hubo pequeñas deliberaciones entre los grupos del exilio y el del «Reich». Cuestiones de proceder de la lucha de resistencia, por ejemplo en las empresas, pero sobre todo de orientación política como la valoración de las experiencias

33. Inicialmente se preveía Brno como sede de la Conferencia. La dirección en el exilio de la socialdemocracia austríaca en torno a Otto Bauer quería que se hiciera allí con tal de prestar ayuda, contra lo cual sin embargo las autoridades nazis, que habían conseguido saber de él, intervinieron junto al gobierno checo. Así se dice en BRANDT, Willy, Links und frei,... op. cit., p. 192. 
con los frentes populares, la posibilidad de un partido revolucionario únificado o la evolución política de la Unión Soviética estuvieron en el orden del día. También se manifestaron fuertes tensiones internas en el partido, lo que tuvo que conducir a la separación de una minoría inmediatamente después de la Conferencia. Willy Brandt dejó constancia de la atmosfera vivida en esa conferencia en sus Memorias ${ }^{34}$. El órgano del SAP Neue Front también publicó un informe en el periódico con informaciones sólo insinuadas por razones conspirativas que pudo ser complementado con las actas. ${ }^{35}$

Max Diamant, que llegó tarde después de un difícil viaje, lo cual redujo las posibilidades de debate ${ }^{36}$, entregó un informe detallado sobre España que empezaba introduciendo saludos de los representantes del POUM y de los miembros del ILP en Barcelona. En él Diamant relataba exhaustivamente los meses precedentes, los conflictos políticos entre las diferentes fuerzas en torno a la cuestión de si seguir impulsando la Revolución o detenerla, y destacaba el papel del POUM. Juzgaba críticamente el peso creciente de la Unión Soviética, que apoyaba la lucha mediante el suministro de armas pero al mismo tiempo quería frenar la revolución y dirigía una campaña contra el POUM, la fuerza más revolucionaria. Ahora ya no veía al POUM tan fuertemente influenciado por el trotskismo. Sí que percibía fuertes contradicciones en su política y veía que era el más débil en relación a otros partidos. No obstante sí se mostraba optimista respecto a la posibilidad que se constituyera un bloque revolucionario con fuerzas de otras organizaciones, especialmente con los anarquistas hegemónicos, lo que también tendría un impacto en otras corrientes.

El debate fue (por razones de tiempo) relativamente corto, o al menos eso se presume del acta. Willi (¿Willy Brandt?) habló a favor de una nítida declaración de solidaridad con el POUM. Sin embargo, también señaló las consecuencias negativas que podía tener una asociación con el trotskismo. Mientras que Jacob Walcher, al referirse a esto, advirtió que el POUM tenía que «ir paso a paso» para no acabar aislado, Paul Frölich se opuso. En su discurso de clausura Diamant advirtió contra la creciente influencia del PSUC, la rama catalana del PCE, que podía contar con el apoyo del armamento ruso y ejercer una política contrarrevolucionaria. Pero el POUM tenía todas las posibilidades de llamar a las masas en contra de esto. Se tenía que apoyar más enérgicamente al POUM y en ese senti-

34. BRANDT, Willy, Links und frei,... op. cit., pp. 191-196.

35. "Parteikonferenz der SAP» en Neue Front, números 2 / 3 (comienzos de febrero de 1937); las transcripciones escritas de las actas del Congreso, en parte fragmentariamente, en parte con diferentes versiones, en Carpeta 3, SAP-Archiv. Breves explicaciones de la Conferencia, en parte con el falso lugar de Brno, en BREMER, Jörg, Die Sozialistische Arbeiterpartei Deutschlands,... op. cit., p. 208; BUSCHAK, Willy, Das Londoner Büro,... op. cit., p. 282; LORENZ, Einhart, Willy Brandt in Norwegen,... op. cit., pp. 170-172. Numerosas referencias en parte en los documentos publicados, en parte en las notas del editor en BRANDT Willy, Berliner Ausgabe, Bd. 1,... op. cit., pp. 41, 44, 47, 64, 252-264, 356, 523, 528.

36. Así se dice en una carta que escribió después de su regreso a París el 13 de enero a Blachstein y Wolf en Barcelona (Carpeta 165, documento 9). 
do había habido un desentendimiento. La declaración de apoyo al POUM propuesta por Willi fue aprobada por unanimidad ${ }^{37}$. Todas las fuerzas políticas en España fueron llamadas a la unidad y prevenidas contra el enfrentamiento interno. Sin embargo eso no era una declaración explícita de apoyo a las posiciones políticas del POUM ni especialmente a sus críticas a un Frente Popular. En los siguientes meses se vería que eso no podía ser.

En el mismo número del Neue Front en el que se informó sobre la Conferencia y se publicó el texto de solidaridad con el POUM, empezó una entrega en dos partes sobre «la senda de la Revolución española» ${ }^{38}$. El autor fue señalado como "un camarada que tuvo la posibilidad de formarse un juicio en el sitio y el lugar». Que esa persona fuera Max Diamant es más que probable. Más considerablemente que en su informe, que destacó el papel del POUM en particular y lo ligó detalladamente con los enfrentamientos entre las diversas fuerzas políticas, este artículo dibujaba un amplio panorama de la situación social y política, desde la situación en Cataluña hasta la del gobierno central republicano. Estaba teniendo lugar una restricción de la revolución espontánea de las masas después del 19 de agosto en base a la falta de liderazgo y al prestigio e influencia que estaba ganando la Unión Soviética o, mejor dicho, el PCE, debido al suministro de armas en España, detrás del cual se escondía sin embargo un rechazo de cariz reformista a la Revolución. La influencia que estaba ganando Stalin representaba un peligro para la Revolución. La política del POUM, que con su participación temporal en el gobierno de Cataluña hasta ser apartado por las presiones de los comunistas del PSUC había demostrado que no era un partido sectario, estaba totalmente justificada. La crítica de Diamant al POUM no se hizo oír. Al contrario, aparecía en ese texto como un partido que entendía la política de frentes populares como el SAP. Sin embargo la campaña dirigida contra el POUM por ser una fuerza verdaderamente revolucionaria amenazaba con desencadenar una lucha fratricida.

Esa gran preocupación, ya expresada en la Conferencia, causaba inquietud en el SAP ante la posibilidad de un choque dentro del campo republicano, y esa preocupación dio lugar a que el SAP fuera a visitar a Otto Bauer, una de las personalidades más respetadas de la socialdemocracia internacional y líder del partido austríaco, y entonces en el exilio en Brno, en Checoslovaquia. Walcher, Frölich, Brandt y Diamant no sólo querían agradecerle por su ayuda en la organización de la Conferencia del SAP, sino informarle sobre todo de esa evaluación e iniciar las intervenciones correspondientes. En base a sus experiencias personales, Max Diamant le advirtió, así lo expone Brandt en sus Memorias, «que los preámbulos para una confrontación violenta en el bando del movimiento de los trabajadores están en marcha con espeluznantes consecuencias y celeridad». Otto Bauer, que estaba perfectamente bien informado de la situación en España, explicó en su respuesta que él quería ponerse en contacto para hablar de eso con Luis Araquistáin, el embajador español en París y confidente cercano del presidente Largo Caballero. Sin

37. Publicada en Neue Front, número 2 / 3 (comienzos de febrero de 1937).

38. La última parte se publicó en el número 4, a mediados de febrero de 1937. 
embargo no habló nada acerca de una campaña pública. Para él, tener influencia en las «instancias decisivas» de Moscú era la única estrategia alentadora. Por lo demás, su impresión era que el POUM era un partido trotskista a pesar que recientemente hubiera llegado a él una declaración en la que lo negaba categóricamente. Si Otto Bauer posteriormente realizó esfuerzos concretos, no tuvo éxito. De todas formas, esa conversación fue sin duda más útil y beneficiosa que la realizada por Walcher y Diamant con el jefe de la sección alemana del Partido Comunista de Checoslovaquia, para quien los del POUM eran meramente trotskistas contrarrevolucionarios ${ }^{39}$.

Esa Conferencia tuvo aún otra consecuencia. Una minoría de la dirección desde hacía un tiempo en el exilio y el grupo del SAP en París rompieron ahora con el Partido. Esa minoría sentía malestar ante el curso de la política de los frentes populares y abogaba por una postura más agresiva contra el estalinismo. Sus líderes eran el segundo secretario de la oficina de relaciones exteriores, Walter Fabian, y Erwin Ackerknecht, con el nombre en el partido de E. Bauer, que había llegado por primera vez al SAP procedente del trotskismo en 1934 (y que posteriormente se haría conocido como historiador de la medicina. Ninguno de los dos había participado en la Conferencia de Katowice (por razones desconocidas). En las semanas que siguieron a la Conferencia, se separaron dándose el nombre de Gruppe Neuer Weg (Grupo Camino Nuevo). El grupo no sólo rechazaba cualquier acercamiento al frentepopulismo, sino que igualmente rechazaba la concepción de un partido revolucionario único y a medida que fue pasando el tiempo se solidarizó con el POUM por las críticas que le venían desde el SAP ${ }^{40}$. Importante era que Peter Blachstein, como representante de la organización de Juventudes del SAP en Barcelona se pasara a ese grupo, lo que llevaría inmediatamente por un lado a enfrentamientos con Max Diamant y luego con Willy Brandt, y por el otro a enfrentamientos del SAP con el POUM, ya que éste se veía cercano políticamente al Neuer $W_{e}{ }^{41}$.

39. La referencia a ello en BRANDT, Willy, Links und frei,... op. cit., p. 200 es muy escasa, y más detallada aparece en la carta de Diamant a Blachstein y Wolf ya mencionada más arriba (nota 36), complementada con la conversación oral del 26 de febrero de 1981. En su carta Diamant no habla de Moscú, sino de "La Meca» aunque queda por ver si esto se debió a una especie de encubrimiento o a la ironía, o tal vez a ambas cosas. La más reciente y realmente muy detallada biografía de HANISCH, Ernst, Der große Illusionist: Otto Bauer (1881 - 1938), Viena, Böhlau, 2011, no menciona ese episodio.

40. En general sobre el grupo Neuer Weg BREMER, Jörg, Die Sozialistische Arbeiterpartei Deutschlands,... op. cit., pp. 206-211; BUSCHAK, Willy, Das Londoner Büro,... op. cit., p. 282. Inmediatamente después de su fundación el grupo comenzó a publicar Spanien-Informationen, que apareció hasta finales de 1937 (número 5 / 6), en FABIAN, Walter, Die Presse der Sozialistischen Arbeiterpartei Deutschlands im Exil 1933 - 1939,... op. cit., 10.

41. En BRANDT, Willy, Links und frei,... op. cit., p. 246, sólo hay breves referencias en relación a su estancia en Barcelona sobre su relación tormentosa con Blachstein y alusiones a que incluso después de 1945 la relación entre ambos se hizo más agobiante. 
Max Diamant en Barcelona II (20 de febrero a 11 de abril de 1937)

A mediados de enero Diamant volvió de su viaje a Checoslovaquia de vuelta al Sena, como se puede extraer de la carta con sus impresiones y valoraciones ya citada anteriormente, que envió de inmediato a Barcelona ${ }^{42}$. En el camino de vuelta también se había detenido en Praga y Basilea para informar de la situación en España. En Praga había un grupo local del SAP, del cual informó de "feroces contradicciones» en sus filas sin que trasladara nada en cuanto al contenido de esas contradicciones. Obviamente las posiciones defendidas allí eran conocidas en Barcelona. En Basilea había un «círculo de jóvenes socialdemócratas de izquierda y trotskistas", y en consecuencia oportunamente se defendió de la crítica trotskista al POUM. En la propia París el debate sobre España con el grupo del SAP de allí tuvo lugar en la primera quincena de febrero ${ }^{43}$. No nos han llegado las respuestas a Diamant ni un informe o escrito sobre el debate de París. Es presumible no obstante que las discusiones giraban en torno de la exclusión de la minoría o, más concretamente dicho, de su constitución como el nuevo Gruppe Neuer Weg.

A principios de febrero la dirección del SAP ya había establecido que Diamant volviera a Barcelona, para cuatro semanas. A continuación iba a ser enviado un nuevo representante del SAP, que hasta entonces había estado en Palestina, Boris Goldenberg. Brandt escribió en sus Memorias, posiblemente por un error de memoria, que su envío a Barcelona como relevo de Diamant ya había sido decidido en Ostrava. En realidad Brandt volvió desde allí nuevamente a Oslo. Pero en Noruega tuvo inmediatamente problemas con la policía, que tenía una buena idea de sus actividades en el extranjero. Por eso, a Brandt se le dio en ese momento, en febrero, la orden de ir a Barcelona, pero como representante de las Juventudes del SAP. Con todo, esto fue planteado sólo provisionalmente, en vistas a un Congreso de las Juventudes paralelo al del Buró de Londres, porque como representante permanente de las Juventudes del SAP en la metrópolis catalana ya se encontraba Peter Blachstein ${ }^{44}$.

Max Diamant se encontraba en Barcelona nuevamente el 20 de febrero de 1937, como se desprende de un largo informe sobre sus primeras impresiones y discusiones que remitió cinco días después a la dirección del SAP45 ${ }^{45}$ En primer plano estuvo la discusión con los miembros del SAP en la ciudad, que llegó a durar dos días y medio. Informó detalladamente sobre la conferencia de Katowice y compartió las valoraciones desarrolladas por el SAP. Se encontró una oposición violenta, especialmente de Blachstein, pero

42. Ver nota 36.

43. El archivo de SAP contiene un largo texto sobre España con el encabezado escrito a mano «Informe sobre España del compañero Diesel en el Sena 6 y 13 I|».

44. BRANDT, Willy, Links und frei,... op. cit., p. 215; LORENZ, Einhart, Willy Brandt in Norwegen,... op. cit., p. 178.

45. Carpeta 166, documento 21 (en extracto), documento 22 (completo). 
también por parte de Herbert Wolf. Las informaciones sobre la exclusión de la minoría discordante en París ya habían llegado a Barcelona, pero sin embargo se opusieron vehementemente al Ilamamiento a un Frente Popular alemán en diciembre en París con el apoyo de SAP. Max Diamant y Willy Brandt habían sido firmantes de su parte ${ }^{46}$. Esto había caído en el POUM, pero también en otros muchos partidos de izquierda socialista y comunistas opositores a Stalin representados en Barcelona, como una bomba, como decía Diamant, ya que se había agudizado la campaña impulsada por el Partido Comunista contra el POUM bajo el signo del Frente Popular ("contra sus enemigos trotskistas contrarrevolucionarios»). Entre los 13 miembros del SAP que se encontraban en España esa crítica fue muy apoyada. Diamant dejaba claro al final de su informe que el conflicto político pronto también tendría consecuencias organizativas.

La situación política general había cambiado drásticamente en los dos meses previos a su regreso a Barcelona. No sólo en la atmosfera, sino también en la vida política oficial, algo de lo que se percató al observar la presencia de nuevas fuerzas militares y policiales: "El movimiento vuelve a difuminarse, la Revolución va decayendo día tras día». Por todas partes se hacía notar la campaña del Partido Comunista y sobre todo sus difamaciones contra el POUM. Al mismo tiempo la República había tenido que hacer frente a una serie de fracasos y derrotas militares. Como fruto de esa situación, Diamant observó crecientes síntomas de tendencias a la resignación o al menos de incertidumbre, de duda. Solamente una nueva ofensiva en el frente podía volver a insuflar ánimo y vida al movimiento revolucionario. Diamant veía fundamentadas en las crecientes dificultades las tensiones dentro del POUM, en parte también con ataques en su prensa al SAP por su perseverancia con la idea del frente popular ${ }^{47}$.

Diamant permaneció casi dos meses en Barcelona. Sus numerosas otras cartas (en el Archivo del SAP se encuentran un total de 12 cartas de la época de su llegada a Barcelona hasta finales de marzo ${ }^{48}$ ) dejan constancia del creciente agravamiento de la situación. Esto tenía que ver, por un lado, con la creciente confrontación entre los campos políticos, que apuntaba a eliminar las fuerzas revolucionarias y darle al Partido Comunista la voz cantante. Esto llevó al empeoramiento de la relación entre el POUM y el SAP. En un primer momento iba a dimitir en la dirección del POUM Julián Gorkin, que había trabajado estrechamente con el Buró de Londres como Secretario Internacional del POUM, por las agudas críticas al Frente Popular, algo que Diamant lamentó, aunque luego cambió de idea. Juan Andrade tuvo más peso a partir de ese momento en lo relativo al trabajo in-

46. Publicado en LANGKAU-ALEX, Ursula, Deutsche Volksfront 1932-1939, Bd. 3,... op. cit., pp. 279-284; sobre las causas ver el volumen 2, pp. 535-541, 551-564.

47. La organización juvenil del POUM se apresuró a hablar del intent del exilio alemán en un artículo en su órgano a finales de febrero titulado «El más reaccionario Frente popular, que se conoce». TOSSTORFF, Reiner, Die POUM in spanischen Bürgerkrieg,... op. cit., p. 301.

48. Carpeta 166, documentos 21-34. Véase también la documentación de la nota 32. 
ternacional, especialmente en lo tocante a la colaboración con los representantes de las diferentes organizaciones extranjeras de izquierda en Barcelona. En lo relativo al trabajo con contactos internacionales Andrade estrechó vínculos con el austríaco Kurt Landau, que había estado activo en los años 20 en el KPÖ (Kommunistische Partei Österreichs, Partido Comunista de Austria) y había participado luego en el movimiento trotskista, con el cual había roto no obstante en la década de 1930 por una serie de cuestiones políticas y estratégicas para fundar una organización propia (Der Funke, La chispa) ${ }^{49}$.

Era sobre todo la organización de Juventudes del POUM (la Juventud Comunista Ibérica) la que expresó una crítica abierta al SAP, que de hecho fue apoyada por Peter Blachstein, como Diamant tuvo que notificar. Diamant opinaba que se podía afirmar que el POUM pretendía que todo se llevara a la lógica de "o con ellos o contra ellos». La totalidad de la izquierda independiente internacional debía pasar a apoyarles. Incluso tuvo que lamentar encontrar esa actitud en el propio Gorkin, para desengaño suyo ${ }^{50}$. A Diamant le parecía inevitable a largo plazo un enfrentamiento abierto con el POUM, lo que también tendría que plantear la cuestión de la relación con el Buró de Londres y con el SAP, a no ser que el POUM pusiera en marcha una nueva organización internacional. La cosa pendía de un hilo.

En un primer paso el POUM decidió reorganizar al grupo germanohablante. Al fin y al cabo, los pocos miembros del SAP representaban allí una minoría. Si bien Diamant, como representante de un partido alemán en el Buró de Londres, después de su llegada a Barcelona en octubre había dirigido el «trabajo alemán» del POUM (lo que afectaba fundamentalmente a la propaganda y especialmente a la dirección de Spanische Revolution), su ahora portavoz Landau podía apoyar en la crítica severa a la política de Frente Popular no sólo a Blachstein, sino también igualmente al grupo más grande de miembros del KPO, la llamada "oposición comunista de derecha" alrededor de Heinrich Bradler y August Thalheimer.

49. Sobre Landau, que en el otoño de 1937, después de la supresión del POUM, fue arrestado y asesinado por el servicio secreto soviético, véase la rigurosa biografía, que también detalla su época en Barcelona, de SCHAFRANEK, Hans, Das kurze Leben des Kurt Landau: ein österreichischer Kommunist als Opfer der stalinistischen Geheimpolizei, Viena, Verlag für Gesellschaftskritik, 1988.

50. Gorkin había ido y venido notablemente en esos meses, habiendo comunicado a fines de febrero en una reunión de la Subsecretaría del Buró de Londres su renuncia como Secretario Internacional del POUM, pero luego retiró su dimisión debido a los apoyos y ánimos para continuar que recibió por parte de la Subsecretaría. «Incluso aunque mantenía diferencias en la acción internacional del POUM, por ejemplo con Andrade, seguía siendo su portavoz a nivel internacional, incluido en el Buró de Londres. A finales de marzo dijo en un artículo programático (...) que el poumismo y el anti-poumismo eran los criterios decisivos en el movimiento obrero internacional. En una reunión del Buró el 5 de marzo exigió, entre otras cosas, el rechazo de la política de frente popular y la discusión de la política del SAP en Barcelona como parte de la discusión de la plataforma para una nueva internacional.» TOSSTORFF, Reiner, Die POUM in spanischen Bürgerkrieg,.. op. cit., p. 301. 
Con todo, antes que la situación se emponzoñara hasta llegar a un conflicto abierto, Diamant volvió el 11 de abril de 1937 a París, donde viviría hasta los primeros días de la Segunda Guerra Mundial ${ }^{51}$. El SAP puso en el lugar de su antiguo representante al recién llegado a Barcelona Willy Brandt (dejando así a un lado a Boris Goldenberg, que nunca llegó a Barcelona), quien en un primer momento había sido enviado a Barcelona sólo con deberes relativos a la Organización de Juventudes. Además en ese primer momento sólo tenía que complementar un poco y ayudar a Blachstein. Pero cuando éste último fue quitado del medio por no haber estado al lado del SAP en relación a la formación del grupo Neuer Weg junto con las grandes simpatías que por eso encontró en la organización de Juventudes del POUM, Brandt fue llamado a ocupar su lugar y tuvo que hacer valer enérgicamente en primer lugar ante el POUM que era el único representante oficial de la Organización Juvenil del SAP en el Buró Internacional Juvenil ${ }^{52}$.

Y ahora Brandt también se hizo cargo, con la despedida de Diamant de Barcelona, de su trabajo como representante del partido. Tal vez usó un estilo ligeramente diferente, posiblemente también debido a su experiencia con tareas periodísticas, especialmente en la prensa obrera noruega. Aunque viajó mucho y cultivó contactos más amplios en el POUM más allá de su círculo directivo en Barcelona, también tuvo contactos y llegó a un heterogéneo espectro político dentro del partido. Esto indican sus cartas. Así, Brandt informó detallada y extensamente a los líderes del SAP de sus conversaciones con los portavoces del POUM en Valencia y en Sabadell, quienes criticaron las posiciones de la dirección del POUM en lo concerniente a la cuestión de los frentes populares y que en opinión de Brandt esgrimían argumentos más próximos a los del SAP53. En el fondo, sin

51. La fecha se desprende de una comunicación suya al representante de una organización holandesa en Barcelona (Carpeta 165, Doc. 1), así como de una referencia en una carta de Willy Brandt, en BRANDT Willy, Berliner Ausgabe, Bd. 1,... op. cit., p. 298.

52. Sobre el envío de Brandt a Barcelona consúltese nota 45; sobre la pretensión de representar al SAP en el Buró Juvenil véase su carta al Secretario general de la Organización Juventil del POUM, Wilebaldo Solano, del 3 de abril (WBA). En la circular 11/37 de finales de mayo (WBA), la dirección del SAP comentó una vez más el caso de Sander (esto es, de Peter Blachstein). Aunque éste fue enviado a Barcelona como representante de la Organización juvenil del SAP, pronto apareció allí como representante del grupo Neuer Weg. Le había explicado a Diamant que aparecería en la prensa del POUM cargando contra la política del Frente Popular del SAP, a lo que Diamant le hizo ver que esto era incompatible con la membresía al partido. Después de que los líderes del partido le pidieran que fuera a París y luego, después de una conversación previa con Neuer Weg, Diamant insistió en sus posiciones, y el 3 de mayo Blachstein encontró la pérdida de su pertenencia al SAP. También es necesario admitir que su expulsión del partido generó críticas, especialmente entre los miembros del SAP que estaban combatiendo en el frente.

53. Esto se extrae de una recopilación de sus cartas a la dirección del SAP similar a la recopilación de cartas de Diamant anexadas a una circular (nota a pie de página 32): «Sobre la cuestión española: (a partir de las cartas del camarada Willi). Material informativo interno n II». Una visión ge- 
embargo, esto no dejaba ver un cambio de rumbo en el cada vez mayor distanciamiento político con el POUM. La cuestión determinante seguía siendo la postura sobre la política de frentes populares.

Esto fue aún más cierto cuando el conflicto político se agravó hasta el punto de llegar a principios de mayo a verdaderos choques violentos, con comunistas y nacionalistas catalanes por un lado y anarquistas y poumistas por el otro enfrentándose los unos a los otros. George Orwell describió impresionantemente los combates entre barricadas por las calles de Barcelona en su Homenaje a Cataluña. Ese conflicto hizo todavía más difícil la situación de Brandt, representante del SAP, que llegó incluso a participar en los intentos para alcanzar una especie de alianza frentepopulista de las organizaciones juveniles de Barcelona, desde las Juventudes del PSUC hasta las del POUM, lo cual fracasó desde el principio. Brandt titula «Entre las sillas» su descripción sobre estos hechos en el primer volumen de sus Memorias, y se remite en ellas también a que en aquel momento criticó (en una carta a la dirección del SAP) a las Juventudes del POUM por haber puesto en marcha una falsa política de unidad ${ }^{54}$.

Después de los Hechos de Mayo la ruptura era inevitable y también de público conocimiento. En el último número de la revista del POUM en lengua alemana e influenciada por el SAP, Spanische Revolution, que ya no sería más publicada, aparecido antes de la disolución del POUM el 16 de junio, se condenaba enérgicamente la política del SAP como una capitulación ante el Frente Popular y una aclimatación a la política estalinista y a la socialdemócrata ${ }^{55}$. En su última reunión el grupo de habla alemana decidió «a petición de Kurt Landau y Peter Blachstein exigir el despido de Willy Brandt del Comité Ejecutivo». En caso que fuera necesario, había que llevarlo más allá de la frontera por la fuerza. Por otro lado, poco antes del 16 de junio, Gorkin confirmó a Willy Brandt que era leal al POUM y le pidió que continuara editando Spanische Revolution ${ }^{56}$.

La respuesta detallada del SAP a los ataques del POUM, el resumen general de sus críticas al POUM, fue formulada dos meses después por Willy Brandt en el documento antes mencionado dirigido a la dirección del SAP, que más tarde fue publicado como un folleto bajo el título Ein Jahr Krieg und Revolution in Spanien («Un año de guerra y revolu-

neral de las crecientes luchas internas en el POUM, lo que probablemente habría llevado a una fuerte confrontación dentro del partido en el Congreso previsto para la segunda quincena de junio, tal vez incluso a una escisión, en TOSSTORFF, Reiner, Die POUM in spanischen Bürgerkrieg,... op. cit., pp. 237-248.

54. BRANDT, Willy, Links und frei,... op. cit., p. 236.

55. "Resolution des Exekutiv-Komitees der POUM über die Politik der S.A.P.», Die spanische Revolution, 7 (finales de mayo de 1937). De todas formas, ya se había publicado en español el 1 de mayo en el órgano principal del POUM. Vid. TOSSTORFF, Reiner, Die POUM in spanischen Bürgerkrieg,... op. cit., p. 302.

56. TOSSTORFF, Reiner, Die POUM in spanischen Bürgerkrieg,... op. cit., p. 303. 
ción en España»5). Que una declaración así de detallada no fuera formulada por Max Diamant ${ }^{58}$, que había estado mucho más tiempo en Barcelona, quizá pueda sorprender. No obstante, Diamant a mediados de abril, nada más regresar a París, trasladó al Partido Laborista Independiente británico una carta en la que describió minuciosamente sus experiencias en el trabajo internacional y sus relaciones (en su conjunto positivas) con Gorkin y su más bien problemática relación con Juan Andrade. Afirmaba que se podía constatar una creciente tendencia trotskista en el POUM, especialmente en su dirección. Aun cuando esto no necesariamente significaba que el POUM pretendiera unir fuerzas con los partidarios "correctos» de Trotsky, sí comprendía en cualquier caso aquellos grupos que habían desafiado a Trotsky táctica u organizativamente pero que mantenían concepciones políticas de fondo (y eso significaba sobre todo un rechazo a la política frentepopulista de la izquierda) y tenían como meta una nueva Internacional, en la que el POUM estaría justamente en el centro ${ }^{59}$. También posteriormente Diamant debería proporcionar en los Congresos del Buró de Londres similares elementos de discusión ${ }^{60}$.

Sin embargo, las impresiones sobre España presentadas por Brandt en julio no sólo estaban actualizadas en un sentido directo. Willy Brandt había tenido que gestionar las diferencias con el POUM ante los Hechos de Mayo en una situación mucho más peliaguda pero, sobre todo, había sido el testigo directo de unos hechos que habían puesto punto y final a las expectativas revolucionarias que se habían originado en los meses inmediatamente posteriores al 19 de julio de 1936. La supresión del POUM con el arresto de muchos de sus miembros, que comenzó seis semanas después de los Hechos de Mayo, no solo le había obligado a huir. En particular los compañeros de lucha extranjeros del POUM, especialmente los procedentes de países con dictaduras fascistas, fueron entonces la presa fácil, un blanco predilecto de la represión, y por eso Peter Blachstein tuvo que pasar unos meses en la cárcel hasta que, afectado de salud y duramente golpeado, pudo salir, mientras que Kurt Landau, que primero se escondió, fue detenido y seguramente asesinado por el servicio secreto soviético ${ }^{61}$. En esta situación, sin embargo, el

57. Véase nota 6 .

58. No obstante, la dirección del SAP ya lideró a principios de mayo una larga discusión sobre España con su participación. (el protocolo del 2 de mayo en la carpeta 9).

59. Su carta del 18 de abril se encuentra en el anexo a la circular de la dirección del SAP n 9/37 del 25 de abril.

60. Sus intervenciones aparecen en las actas extraoficiales de las reuniones del Buró de Londres incluidas en los boletines informativos de la dirección del SAP; por ejemplo, las de la reunión del 11 de mayo en no 10/37 del 15 de mayo, las de la del 5 de junio en n० 13/37 del 14 de junio, WBA.

61. La bibliografía sobre la represión estalinista es muy amplia. Especialmente la apertura, al menos parcial, de los archivos soviéticos ha permitido conocer numerosos detalles y ha permitido respaldar hechos que hasta hace poco sólo se sospechaban. Véase algo de eso en TOSSTORFF, Reiner, Die POUM in spanischen Bürgerkrieg,... op. cit., pp. 316-322; El POUM en la revolució espanyola,... op. cit., pp. 251-308. Particularmente sobre el destino de los emigrantes de izquierda de 
informe resumido de Brandt contenía no solamente un análisis detallado de la situación en España y de sus causas y una crítica a la políticas del POUM, que calificaba como de "ultraizquierda» o "sectaria», sino que también incorporaba una llamada a la solidaridad: "a aquellos defensores de otra opinión que pretendan aniquilar a los trabajadores revolucionarios por medio de la falsedad, la calumnia más soez, la mentira y el terror,... ¡hay que detenerles!».

\section{Observaciones finales}

Una generación entera de izquierdistas (y especialmente las fuerzas independientes comunistas y socialdemócratas) fue moldeada por las experiencias en España, como se desprende de numerosas descripciones biográficas y sobre todo autobiográficas. Esto afectaba sobre todo la postura hacia la Unión Soviética. Ciertamente, esto también es aplicable a Max Diamant, aunque no dejara escritos grandes detalles. España fue el último baluarte para frenar el avance del fascismo. Que ese baluarte cayera no sólo se debió a la ayuda de Hitler y Mussolini en favor de Franco o a la negación de ofrecer apoyo a la República española por parte de las potencias occidentales verdaderamente amenazadas por el fascismo, sino también a la actitud de la Unión Soviética y del Partido Comunista con respecto a la izquierda independiente no controlada por ellos. Esto sentaba un precedente de lo que llegarían a saber fuerzas políticas más importantes con más trágicas consecuencias el 23 de agosto de 1939 con la firma del Pacto Ribbentrop-Mólotov.

En junio de 1937 en España no sólo se dieron las medidas persecutorias concretas. Toda la maquinaria propagandística estalinista administró supuestas pruebas de que los «trotskistas contrarrevolucionarios» (esto era, toda la izquierda independiente en conjunto, cualquiera que hubiera mantenido de alguna manera contacto con el POUM) habían actuado bajo las órdenes directas de los fascistas. Esto afectó también como miembro de su dirección a Max Diamant, ya que había estado una serie de meses en Barcelona. Por eso no sorprende que el Deutsche Volkzeitung, el órgano del KPD en el exilio, en un artículo sobre "la deshonra del SAP» pusiera énfasis en su persona junto a la de los cofundadores del KPD Paul Fröhlich y Rosi Wolfstein, que habían sido apartados del KPD y se

habla alemana ZUR MÜHLEN, Patrik von, Spanien war ihre Hoffnung,... op. cit., pp. 66-73, 143-177. Un trabajo ya clásico en torno a sus experiencias como miembro de la dirección del POUM es GORKIN, Julián, El proceso de Moscú en Barcelona: el sacrificio de Andrés Nin, Barcelona, Aymà, 1974. En la edición alemana resumida de esta obra Willy Brandt contribuyó escribiendo el prólogo. Una relación de los nuevos conocimientos a partir de los antiguos archivos soviéticos en VOLODARSKY, Boris, El caso Orlov: los servicios secretos soviéticos en la guerra civil española, Barcelona, Crítica, 2013. 
pasaron al SAP en 1932²: en el artículo se decía que esas personas se habrían conjurado con los «traidores» en España y habrían apuñalado al Frente Popular por la espalda. No dejaba de ser irónico además que en ese incendiario y calumnioso artículo estalinista se pudiera leer la siguiente acusación contra Diamant de una manera tan estridente teniendo en cuenta la clara disociación de Diamant respecto al supuesto trotskismo dentro del POUM: "con una palabra: es el trotskismo de puro estilo". Además era particularmente infame atacar a Max Diamant utilizando su nombre real (en lugar de su pseudónimo político Hans Diesel), puesto que, al haber nacido en 1908 en el antiguo Imperio Ruso, ya había sido declarado "apátrida" en Alemania y por lo tanto tenía una situación aún más difícil que la de los muchos "antiguos ciudadanos del Reich alemán» a los que las autoridades nazis habían hecho retirar la nacionalidad alemana. Sin embargo esto podría haberse dirigido a algo peor, a señalar a sus padres, de lo que hablaremos más adelante.

Aún más mezquinas fueron, debido a que sin duda en España se tenían que tomar aún menos consideraciones hacia la independencia de unos lectores que pudieran informarse de otras maneras, las declaraciones aparecidas en el órgano en lengua alemana de la rama catalana del PCE, el PCUS (que aparecía con el título catalán de La llibertat). A principios de 1938 el representante del KPD en Barcelona «Fritz Arndt» (alias Karl Mewis) hablaba de la "deshonra» que el grupo alemán del POUM había infligido sobre "la emigración antifascista alemana» en su conjunto ${ }^{63}$. Todos los grupos eran atacados, desde el KPO hasta el SAP, que habían estado a las órdenes de Kurt Landau. Se decía que ya en el Congreso de Bruselas del Buró de Londres Gorkin había desvelado la línea política del POUM, que había llevado a su transformación en la Quinta Columna de Franco. Y todo eso, por supuesto, en estrecha relación con Trotsky. Luego, el Congreso de Bruselas había animado al SAP a esforzarse a estrechar el contacto con el POUM con el envío de afiliados. Detalladamente, aunque en general con asociaciones curiosas e incoherentes, los diferentes otros grupos internacionales con vínculos con el POUM eran enumerados como partícipes de la Quinta Columna en aquel escrito. Fueron evidentemente los materiales incautados en los últimos meses de persecución del POUM en innumerables arrestos y registros domiciliarios, los que ahora permitían mezclar en el artículo una amalgama de hechos y absurdas acusaciones de espionaje y actividades quintacolumnistas. El SAP jugó un papel destacado en esa trama quintacolumnista acorde a la visión de ArndtMewis y, en particular, Max Diamant. Éste último no sólo fue nombrado repetidamente

62. "Die Schmach der SAP», Deutsche Volkszeitung, 11 de julio de 1937. La declaración del autor dice: "Un funcionario comunista nos escribe». Sobre la posible autoría de Herbert Wehner, en ese momento miembro de la dirección del KPD y después de la Segunda Guerra Mundial uno de los más destacados líderes del SPD en la República Federal, ver más abajo. Sin embargo en LANGKAUALEX, Ursula, Deutsche Volksfront 1932-1939, Bd. 2,... op. cit., p. 176, se reitera la declaración de otro líder del KPD, según la cual era un artículo largamente preparado en la Secretaría del KPD.

63. ARNDT, Fritz, "Im Schlepptau der Trotzkisten», La llibertat, 11 (comienzos de enero de 1938). 
como Diesel-Diamant, con lo cual se descubría de nuevo su pseudónimo de uso habitual, de manera que todos los lectores, por ejemplo también los nazis de la Oficina Central de Seguridad del Reich (Reichssicherheitshauptamt, abreviado RSHA), podían poseer esa información; también se insinuó que enigmáticamente Diamant se había ido de pronto y apresuradamente de Barcelona en abril de 1937, después que desapareciera allí Marc Rein y no le hubiera dado ninguna información sobre sus contactos (en realidad Marc Rein, que era el hijo del dirigente menchevique en el exilio Rafael Abramowich, fue secuestrado y asesinado por el aparato estalinista en Barcelona, lo que causó un escándalo internacional ${ }^{64}$. Esas insinuaciones le daban la vuelta, tiraban tierra de por medio, a lo que ya entonces era conocido sobre la oscura muerte de Marc Rein, pero la infamia de la acusación se acrecentó aún más con insinuaciones sobre la muerte de Herbert Wolf, cuyo trasfondo aún no había sido bien del todo explicado. El «antiguo menchevique D.» fue señalado así como el instigador de "affaires oscuros" ${ }^{65}$, mientras que otros miembros del SAP como Blachstein fueron mencionados de soslayo. Tan sólo Willy Brandt adicionalmente "disfrutó» del dudoso beneficio de recibir ataques directos, puesto que al fin y al cabo él había sustituido a Diamant en abril y había sido el representante del SAP durante los Hechos de Mayo. De Brandt se decía que había actuado de manera especialmente taimada al haber aspirado a trabajar conjuntamente en el Frente Popular también con los comunistas alemanes en Barcelona. Pero efectivamente era Diamant, del que apenas se sabía nada antes, quien pasó a ser uno de los personajes centrales en la lista estalinista de enemigos, y no sólo por sus actividades durante sus estancias en Barcelona. Había además otro factor: él había tenido experiencias directas en la Unión Soviética y tenía contactos allí, ya que sus padres todavía vivían allí, lo que tenía importancia en el marco del Gran Terror que se inició a partir de 1936. De hecho esto fue puesto de relieve por el entonces miembro del Politburó del KPD Herbert Wehner, que tenía bajo el punto de mira a todo el espectro político de la izquierda independiente no estalinista (o, en su opinión, «trotskismo») y lo vigilaba intensamente para la dirección del partido. En varios memorandos dirigidos a la dirección del Komintern en el transcurso del año 1937 dio detalladas descripciones e informaciones sobre ese espectro político y subrayó en su exposición sobre el SAP el papel de Max Diamant ${ }^{66}$. En uno de sus memorandos al servicio secreto soviético, incluso hizo hincapié en que lo había tildado de trotskista en un

64. Véase la bibliografía detallada en la nota 61.

65. La asociación de Max Diamant a los mencheviques era, por supuesto, pura fantasía, aunque a menudo se repetía en la prensa del KPD. Cuando estuvo en la Unión Soviética entre 1922 y 1927, había sido del Partido Comunista. Después de su huida a Alemania se unió durante un breve período al SPD y luego al SAP.

66. Esto se muestra en detalle y en parte documentado con materiales de archivos soviéticos en MÜLLER, Reinhard, Herbert Wehner-Moskau 1937, Hamburg, Hamburger, 2004, pp. 333, 351, 364, $386,391,470,490,492-497$. 
artículo ${ }^{67}$. Como resultado de todo eso, una delegación del SAP protestó ante la dirección del KPD contra la mención reiterada del nombre de Max Diamant, puesto que ya no sólo estaba perseguido por la Gestapo, sino que también sus padres vivían en la Unión Soviética y al hacer eso se les ponía en un aprieto (de hecho, en ese momento ya habían sido arrestados y asesinados). Naturalmente, las repercusiones concretas de esa denuncia a través de Wehner no se pueden sondear sin tener acceso en los archivos a los dossiers del servicio secreto soviético.

Por supuesto, el aparato estalinista en Occidente no tenía acceso a Max Diamant, a pesar de los ataques en la propaganda de KPD ${ }^{68}$. Para él, la amenaza inmediata la representaba la Alemania nazi, especialmente tras la conquista de Francia en 1940. Logró escapar de la amenaza de persecución huyendo a México. Allí se encontró con compañeros de trayectoria de Barcelona: por ejemplo, el líder del POUM Julián Gorkin u otros que estaban estrechamente asociados con el POUM, como el autor ruso belga Victor Serge o el francés Marceau Pivert, el cual llegó a colaborar con el POUM tras su ruptura con el

67. Íbidem, p. 479. Dado que Wehner no proporcionó ninguna información adicional sobre el artículo en este memorándum, por supuesto no es posible decir exactamente si realmente fue el artículo mencionado anteriormente (nota 62). Sin embargo, el énfasis explícito hecho por Diamant, la producción de una amalgama de POUM, España y el trotskismo, hace que tal suposición parezca plausible. Sin embargo, el énfasis explícito en Diamant y los intentos por conformar una especie de amalgama entre el POUM, España y trotskismo hacen que tal suposición parezca pausible. De todos modos, el 1 de noviembre de 1936 ya se había publicado una larga denuncia contra el SAP y especialmente contra sus "elementos trotskistas» liderados por "Diamant y Co.», firmada con las siglas K. F., abreviatura de su seudónimo Kurt Funk. Este texto aparece reproducido en extracto en MÜLLER, Reinhard, Herbert Wehner-Moskau 1937,... op. cit., p. 61.

68. Sin embargo, el aparato estalinista no se olvidó de nada, como se demostró cuando a principios de los años 50 el recién creado Ministerio para la Seguridad del Estado de la RDA (en alemán Ministerium für Staatssicherheit), la Stasi, intentó de forma especialmente intensa "aclarar" las labores de Brandt en Barcelona como parte de las «investigaciones» en su contra. Había que encontrar algo para poder asignarle un presunto papel de autor intelectual en los Hechos de Mayo, posiblemente en colaboración con los nazis. Esto fue al menos lo que sostuvo el órgano del Partido Socialista Unificado de Alemania (Sozialistische Einheitspartei Deutschlands, SED) Neues Deutschland a principios de la década de 1950. Cuando la Stasi arrestó a una amante temporal de Brandt de Bonn, que estaba empleada como periodista política, en los interrogatorios también le preguntaron si no sabía nada al respecto. WASKE, Stefanie, "Die Spionin, die ihn liebte», Zeit-Magazin, 12 (marzo de 2014), pp. 24-30; MERSEBURGER, Peter, Willy Brandt 1913-1992: Visionär und Realist, Stuttgart, DVA, 2004, p. 410. Es de suponer que estas investigaciones de la Stasi también se dirigieron a Max Diamant, pero con todo Diamant no debería haber despertado demasiado interés generalmente puesto que todavía no había regresado a Alemania. Después de su regreso del exilio mexicano en el año 1962, sus actividades para el sindicato IG Metall estarían bajo el punto de mira de la Stasi, si bien él no ocupó un cargo político comparable al de Willy Brandt y por esa misma razón naturalmente su "observación» no tuvo una importancia similar para la Stasi. 
estalinismo, e incluso al escritor alemán Gustav Regler. Todos ellos estaban en profundo conflicto con el exilio del KPD y el estalinismo mexicano. Así reencontró de nuevo también los anteriores objetos políticos de disputa, que volvieron a girar en torno a la política de alianzas y del frentepopulismo o en torno de la lucha contra el estalinismo, y la vieja guerra de trincheras, al menos parcialmente, se reanudó. En cualquier caso, eso le impidió participar en las agrupaciones de izquierda socialista en México (entre otras cosas en la revista Mundo: socialismo y libertad) durante los años de la Segunda Guerra Mundial ${ }^{69}$.

Sin embargo los viejos conflictos quedaron en nada. Un simple enlace con las posiciones de los años 30 ya no era posible en el marco de las nuevas condiciones que surgieron tras la Segunda Guerra Mundial. Gorkin, en particular, fue uno de aquellos líderes del POUM que, después de la Segunda Guerra Mundial, abandonaron sus propias posiciones socialistas de izquierda de antaño y se acercaron a los socialistas españoles. Un paso importante en su transición política fue el Congreso por la Libertad de la Cultura, patrocinado por los Estados Unidos, que estuvo dominado por las iniciativas periodísticas de Gorkin en lengua española. En los años sesenta también mantuvo un estrecho contacto con Max Diamant ${ }^{70}$. Sin embargo esto último es un capítulo concerniente ya a las implicaciones de Diamant en relación a la Resistencia antifranquista en España, que también emprendió desde su nueva posición en el sindicato IG Metall después de regresar a la República Federal de Alemania en 1962.

69. Comunicación oral del 26 de febrero de 1981. En su diario Victor Serge apuntó el 10 de junio de 1942 que había tenido una larga charla con Max Diamant tres semanas antes. Éste era de la opinión de que la Unión Soviética y Stalin eran más fuertes de lo esperado. Decía que Stalin conseguiría el prestigio de la victoria y se adaptaría a esa situación y se volvería menos violento. "Conclusion: s'accomoder à ces perspectives, louvoyer avec les staliniens» (p. 242). El 20 de junio de 1944 apuntó cosas sobre conversaciones sobre puntos de vista de la guerra mundial y anotó que Max Diamant había expresado su expectativa de que tenía que encontrarse un Badoglio alemán (p. 506). Sobre la distancia de Max Diamant respecto a la revista aparecida desde 1943 Mundo: socialismo y libertad y sobre los conflictos a partir de 1942 con el exilio comunistaón, que llevaron a la constitución de la Union Deutscher und Österreichischer Sozialisten en México, véase POHLE, Fritz, Das mexikanische Exil: ein Beitrag zur Geschichte der politisch-kulturellen Emigration aus Deutschland (1937-1946), Stuttgart, Metzler, 1986, pp. 384-398. Después de 1945, con el inicio de la Guerra Fría, se produjo una reorientación política, y del grupo de los antiguos socialistas de izquierda o comunistas opositores surgió una agrupación que se entendía como grupo en el extranjero del SPD, ahora con su participación.

70. Fundamental sobre esto es GLONDYS, Olga, La guerra Fría cultural y el exilio republicano español: Cuadernos del Congreso por la Libertad de la Cultura (1953-1965), Madrid, Consejo Superior de Investigaciones Científicas, 2012; las páginas 33-41 acerca del exilio de los socialistas de izquierda en México, y sobre los contactos de Diamant con Gorkin en los años 60, las páginas 260 y 270. 